\title{
BIBECHANA
}

A Multidisciplinary Journal of Science, Technology and Mathematics ISSN 2091-0762 (Print), 2382-5340 (Online)

Journal homepage: http://nepjol.info/index.php/BIBECHANA

Publisher: Research Council of Science and Technology, Biratnagar, Nepal

\section{Variability of the atmospheric ozone over Kathmandu using ground-based measurements}

\author{
Narayan P. Chapagain \\ Department of Physics, Patan Multiple Campus, Tribhuvan University, Lalitpur, Nepal \\ E-mail:npchapagain@gmail.com
}

Article history: Received 21 July, 2015; Accepted 30 August, 2015

DOI: http://dx. doi.org/10.3126/bibechana.v13i0.13311

\section{Abstract}

Measurement of the atmospheric total ozone over Kathmandu $\left(27.67^{0} \mathrm{~N}, 85.29^{\circ} \mathrm{E}\right)$ was carried out with a Brewer Spectrophotometer from February 2001 through February 2002. The total ozone data obtained from Brewer instrument are analyzed to study the daily variations of total ozone over Kathmandu on different seasons. The results reveal that day-to-day variations of the total ozone over Kathmandu are seasonal dependent. Total ozone values are relatively high in summer and spring seasons (up to 327 DU) and low ( 213 DU) during the winter season. The low ozone concentration would be due to chemical and dynamic destruction processes related to the low temperature and less active photochemical reaction as less intense solar radiations are received during winter season.

CRCOST: All rights reserved.

Keywords: Brewer spectrophotometer; Dobson unit; Ozone depletion; Stratosphere; Total ozone.

\section{Introduction}

A useful general measure of ozone in the atmosphere is the column ozone or total ozone. The total ozone is defined as being equal to the amount of ozone contained in a vertical column with a base of $1 \mathrm{~cm}^{2}$. A convenient measure of total ozone is the Dobson unit (DU). It is the thickness of the total ozone layer in milli atmosphere centimeter if all the ozone molecules are brought to surface at normal pressure and temperature. One DU represents an average atmospheric concentration of approximately one part per billion by volume (ppbv) of $\mathrm{O}_{3}$. The ozone is not distributed uniformly over the globe. Typical amount of ozone vary 230 to $480 \mathrm{DU}$ with a world average of about $300 \mathrm{DU}$ [1]. A level of $260 \mathrm{DU}$ or below this is considered critical and if measurements decline below this, ozone depletion is considered serious at high latitudes.

Stratospheric ozone depletion in the atmosphere, particularly in the Polar Regions, has wide spread concern to the health hazards on earth's surface $[2,3,4,5]$. The downward trend in the total ozone column 
has been well documented for the regions inside and outside of Antarctica after the detection of the Antarctica ozone hole by Ferman and Shanklin [6]. Here total ozone signifies the columnar ozone measurements from surface of the Earth to the top of the stratospheric region. The decrease of total ozone in mid - latitudes in both the southern and northern hemispheres over most of the globe has been detected from the ground- and satellite-based observations $[7,8,9,10]$. Several studies were carried out for the comparison of ground- and satellite- based observations of total ozone [e.g., 11, 12; 13].

The ground-based ozone measurements can be used to determine the climatological characteristics of the ozone distribution. The variability in the total ozone over Thumba India $\left(8^{0} \mathrm{~N}, 76^{0} \mathrm{E}\right)$, was measured with Brewer Spectrophotometer [14] and they have presented the climatological study of atmospheric total ozone. Similarly, Zou has reported the seasonal trends of TOMS ozone over Tibet, China, using the logterm data during 1979 - 1991 [15].

In Nepal a few studies have been carried out during the past years using the ground- and space-based observations and have first reported the variability of atmospheric total ozone over Kathmandu using ground-based measurement by a Brewer Spectrophotometer and space-based observations by Total Ozone Mapping Spectrometer (TOMS) satellite $[16,17]$. The results reported that the total atmospheric ozone over Kathmandu occurred low in winter and large in summer and spring seasons. In this paper, we present the daily total ozone variations over Kathmandu measured by the Brewer Spectrophotometer on different seasons during one-year period from February 2001 to February 2002.

\section{Methodology}

The ozone data used in this study were obtained by using Brewer Spectrophotometer. The Brewer Spectrophotometer, MKII \# 176 has been operating since January 2000 at the Central Department of Physics, Tribhuvan University, Kirtipur, Kathmandu, Nepal $\left(27.67^{0} \mathrm{~N}, 83.29^{0} \mathrm{E}\right)$. The Brewer instrument is an improved optical scheme for observations of total ozone. Kerr and MCElory [11] reported operating systems and about the automation of Brewer Spectrophotometer. It has also the ability to perform spectral scans to quantify the UV radiation that passes through the atmosphere $[18,19]$. There are six exit slits. One is used for wavelength calibration against the $302 \mathrm{~nm}$ groups of mercury lines. The other five are for intensity measurements and are normally set at 306.3, 310.1, 313.5, 316.7, and $320.1 \mathrm{~nm}$. The band pass of each is $0.6 \mathrm{~nm}$ [20]. These spectral intensity measurements are used to determine atmospheric total ozone column and $\mathrm{SO}_{2}$. The accuracy of ozone measurements is estimated to be $\pm 1 \%$ [16]. The data recorded by Brewer instrument are direct sun (DS) ozone measurements and zenith sky (ZS) ozone measurements (17]. The measurements are in Dobson Units (DU). The ozone is measured on every 2 
minutes. In this study, we use the daily average value of ozone data measured by the Brewer instrument. Ozone data are averaged from data collected symmetrically around the daytime.

\section{Results and Discussion}

Total ozone variations associated with solar radiation have been observed using Brewer data. Daily averages of total ozone over Kathmandu have been plotted in Figures 1 to 4 for different seasons. The vertical error bars in the plot indicate the standard deviation of the daily ozone mean.

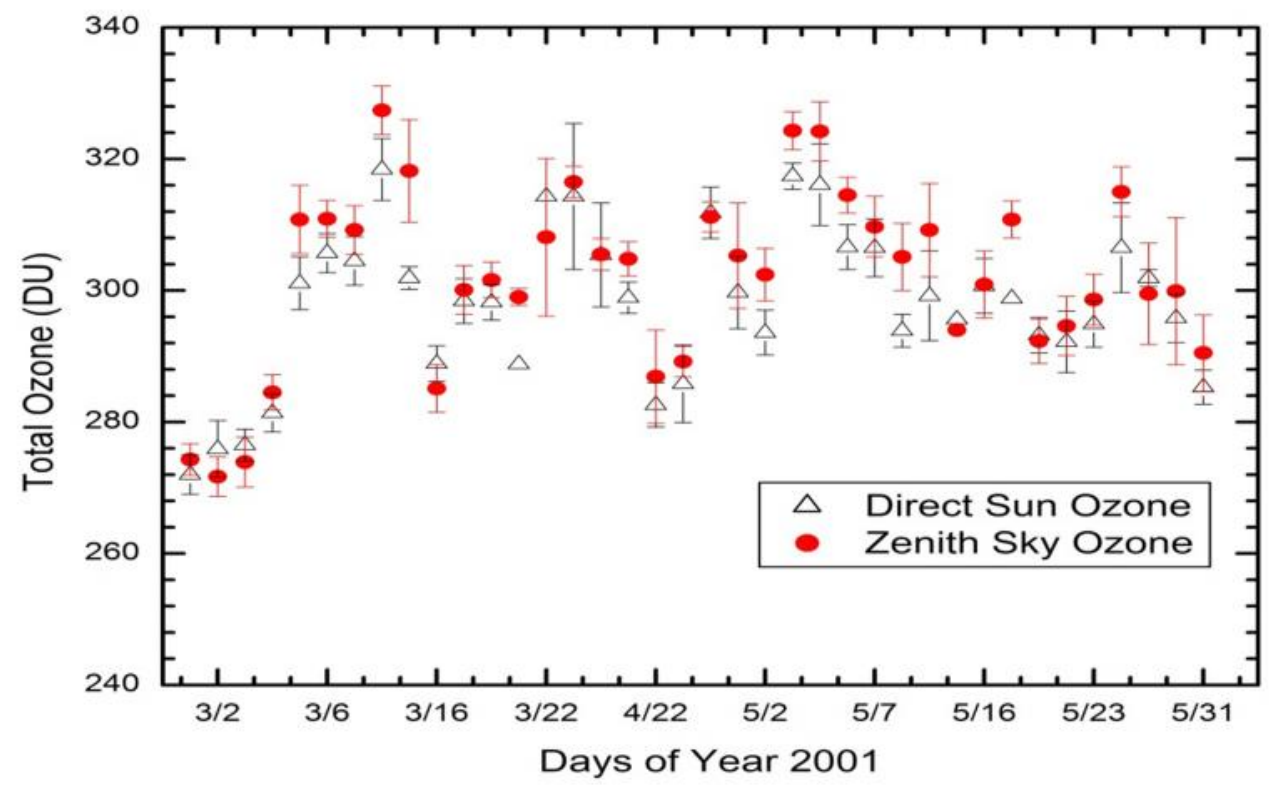

Fig. 1: Daily variations of average value of total ozone over Kathmandu during spring season (MarchMay).

Figure 1 shows the daily averages of Brewer ozone in the spring season (March - May, 2001). In the plot, $\mathrm{X}$-axis represents the days (month/day) of the year, while $\mathrm{Y}$-axis represent total ozone measurements in the Dobson Unit (DU). The data are direct sun (DS) and zenith sky (ZS) measurements. The gap in plot shows the data are missing due to either improper operation of instruments or due to bad weather conditions (cloudy sky or rainy days). The result clearly shows that there is a significant day-to-day variation of total ozone over Kathmandu. The ozone value is minimum ( 270 DU) in early March and increases up to 327 DU in middle of March and early May. We do not have much data available during the month of April. The amplitude of oscillation of ozone data is asymmetric and becomes large in the first week of March and May. 
Figures 2, 3 and 4 are the plot of daily averages of total ozone data in summer (June - August), autumn (September-November) and winter (December-February) seasons respectively. Figure 2 shows that ozone value is large (up to $300 \mathrm{DU}$ ) in first week of June and then slightly decreases during July and August. However, the ozone values are almost remaining same during July and August ( 270-290 DU). Similarly, Figure 3 plots the daily variations of ozone over Kathmandu during the autumn season, which shows the maximum value up to 290 DU and particularly, high ozone concentration during September and October that decrease at the end of October. During this season, ozone value becomes minimum on November (230 DU). Moreover, the ozone data plotted during the winter season (in Figure 4) shows the low value of ozone data with the range of 213-275 DU with lowest values on December and January.

To summarize one-year period of measurements, all data of daily mean total ozone is plotted in Figure 5. The plot illustrates the seasonal variations of total ozone over Kathmandu from February 2001 to February 2002. Figure illustrates the expected trend of total ozone variations. Ozone measurements are low in early February and steeply rise in March and become maxima in spring season. Then ozone value gradually decreases at the end of the summer through autumn and becomes minimum in winter. The highest value of total ozone recorded by the Brewer Spectrophotometer is 327 DU on March 8 and the lowest value is 213 DU on December 20. It can be inferred from the figure that the total ozone over Kathmandu decreases faster during November, December and January than that during other months.

The Figure for minima and maxima agree to expectations for atmospheric total ozone levels in the change of seasons. The expected anomalies in the monsoon did not show in the measurements. From the plots, it is evident that the ozone level mostly decline after the first week of May. In the figures, the steep jumps at the beginning of March and the end of April indicate how total ozone level in spring soared. In the beginning of monsoon in mid June, the total ozone value rises slightly. The pattern of the variation of ozone is similar to either side of the peak. The average total ozone of entire period is $273 \mathrm{DU}$, which is sufficient higher compared to the critical value of atmospheric ozone required to filter the UV radiation, which is considered to be 220 DU. However, the total ozone over Kathmandu in a few days is recorded below the critical value. It clearly illustrates the importance of consistent measurements and study atmospheric ozone over this region.

Figure 6 illustrates the variation of monthly average values of TOMS total ozone and Brewer total ozone over Kathmandu for the period of February 2001 through February 2002. The minimum value of monthly average of TOMS total ozone is 243 DU and 244 DU in November and December, respectively, while the maximum ozone value is 299 DU in May 2001. The amplitude of variations of TOMS ozone is 56 DU in 
absolute units and $22 \%$ in terms of the percentage of the mean. The minimum value of monthly average Brewer total ozone is 244 DU in December 2001 and the maximum value is 302 DU in May 2001. The amplitude of variation of total ozone is $58 \mathrm{DU}$ in absolute units and $21 \%$ in terms of percentage of the mean. The average of entire period is $271 \mathrm{DU}$ for the TOMS ozone, $274 \mathrm{DU}$ for the Brewer ozone. The results show that the variations of TOMS total ozone and Brewer total ozone are symmetric. Hence, from the Figure 6 illustrating the monthly trends, it can be seen that the total ozone over Kathmandu decreases faster during November, December and January than that during other months.

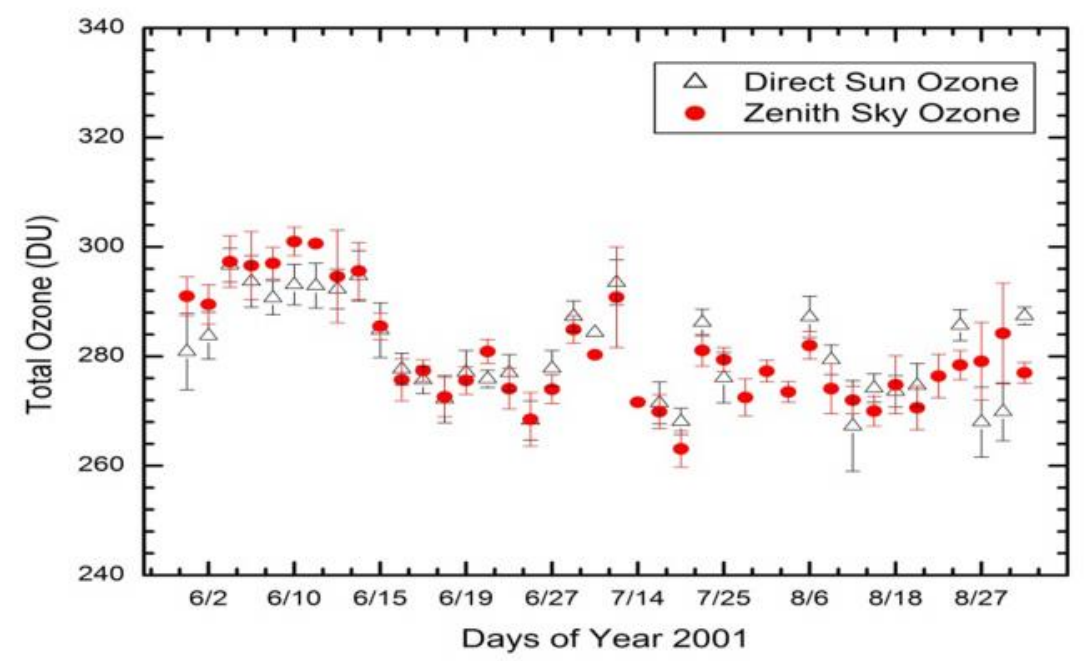

Fig. 2: Daily variations of average values of total ozone over Kathmandu during summer (June-August) season.

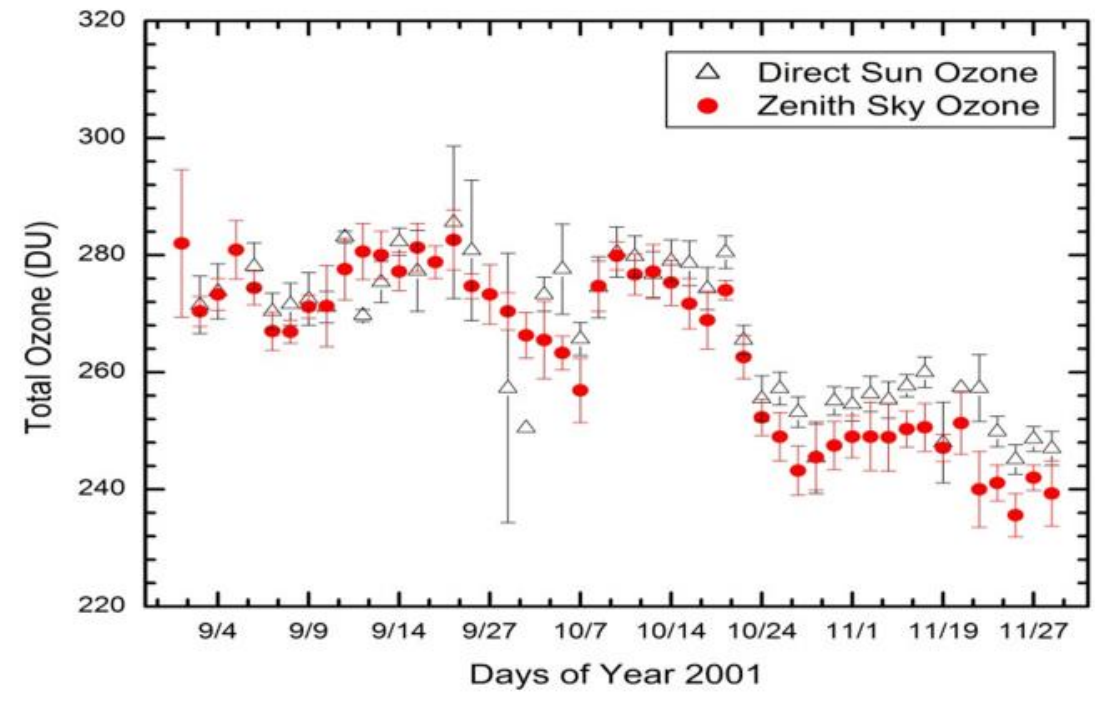

Fig. 3: Daily variations of average values of total ozone over Kathmandu during autumn season (September-November). 


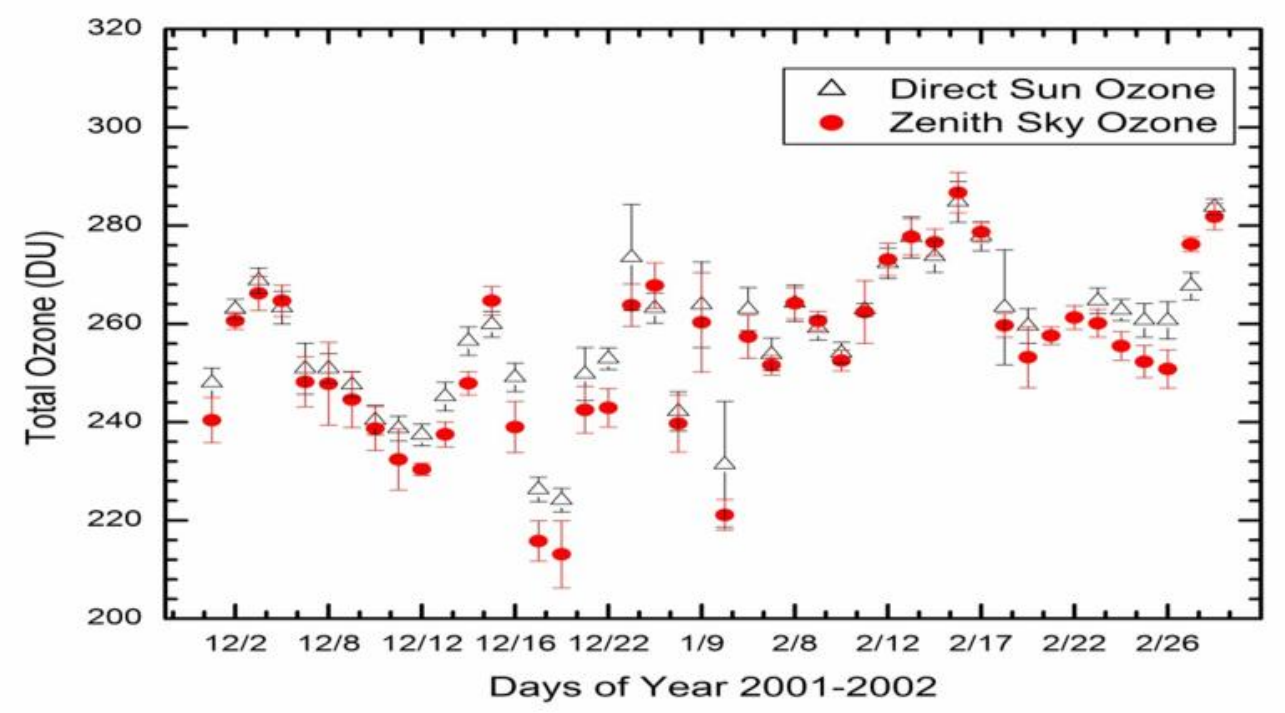

Fig. 4: Daily variations of average values of total ozone over Kathmandu during winter season (December- February).

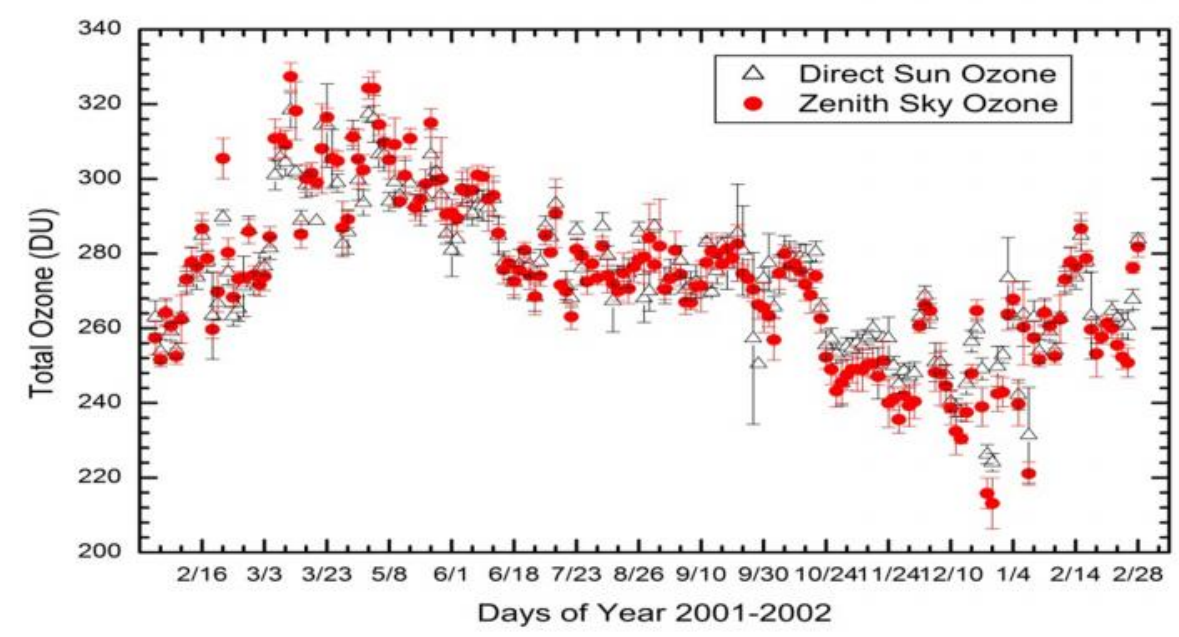

Fig. 5: Daily average values of total ozone measured over Kathmandu during February 2001 - February 2002.

The monthly or seasonal variation of total ozone over Kathmandu is similar to those in other studies [21, 22]. For instance, seasonal variation of total ozone over Tibet [15] varies between 273 DU and 315 DU with minimum in October and maximum in March. Similarly, the total ozone over Thumba, India, is 
minimum in winter (December-January) and maximum in spring (April - May) [23]. In tropical region, the total ozone value is higher in summer and smaller in winter.

The low ozone concentrations over Kathmandu, particularly during winter season, would be caused by chemical dynamic destruction processes related to the low temperature and less active photochemical reaction due to less intense solar radiation. More research is needed to delineate the relative contributions of dynamic, chemical and catalytic processes that cause ozone decrease. It is important to determine how clouds and other climate factors affect the measurements of ozone.

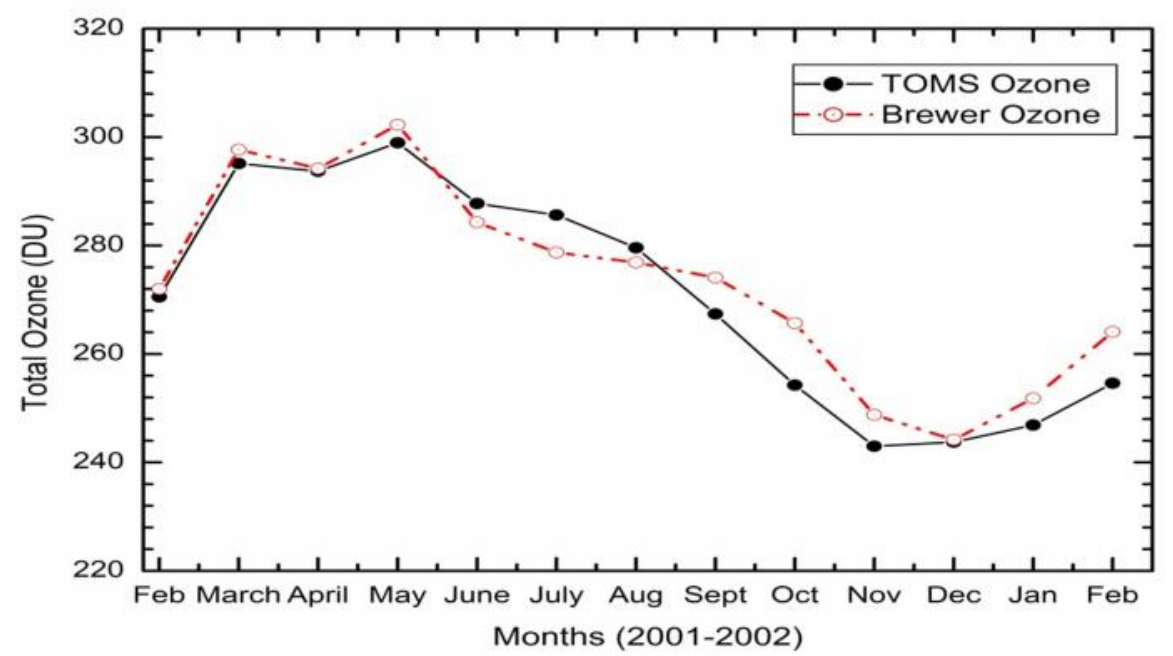

Fig. 6: Monthly averages of total ozone over Kathmandu measured by Brewer Spectrophotometer and TOMS satellite observations during February 2001 - February 2002.

\section{Conclusions}

In this study, we report the atmospheric total ozone over Kathmandu measured with a Brewer spectrophotometer during one-year period from February 2001 to February 2002. The result reveals a significant day-to-day variation of total ozone over Kathmandu. The variation of total ozone is also the functions of seasons, meteorological condition, clouds and solar zenith sky angle. The result illustrates that seasonal variations of atmospheric ozone are significant with maximum in spring (up to $327 \mathrm{DU}$ ) and minimum (go down to 213 DU) in winter season. This implies that ozone values in sunny days or cloud free days are large as the photochemical reaction is predominant for the ozone formation. While total ozone values are low on days having less solar intensity or cloudy days. The low ozone perturbations are stronger in summer than in winter. Diurnal and annual study in ozone level would also provide deeper 
Narayan P. Chapagain/ BIBECHANA 13 (2016) 9-17 : RCOST p.16 (Online Publication: Dec., 2015)

insight into the changes in ozone taking place in this region. The study of seasonal variation of ozone levels can be backed by using the long-term ground- and satellite-based measurements.

\section{Acknowledgement}

Author would like to thank Prof. Dr. Shekhar Gurung, Central Department of Physics, Tribhuvan University, Nepal for providing the ozone data over Kathmandu measured by Brewer spectrophotometer.

\section{References}

[1] World Meteorological Organization (WMO)/United Nations Environment Programme (UNEP): Scientific Assessment of Ozone Depletion: 2006, World Meteorological Organization, Global Ozone Research and Monitoring Project, Report N 50 (Geneva, 2007).

[2] A.P. Alshuller, FAPCA, 37, 12 (1987) 1409 - 1417.

[3] A. Jayaraman, S. Lal, B.H. Subbaraya, Ozone in the Atmosphere, Proc. Quadrennial Ozone Symposium, 1988.

[4] F. Li Stolarski, R. S., and P. A. Newman, Atmos. Chem. Phys. 9, 16 (2009) 2207-2213.

[5] D. W. Waugh, L. Oman, S. R. Kawa, R. S. Stolarski, S. Pawson, A. R. Douglass, P. A. Newman and J. E. Nielsen, Geophys. Rev. Lett. 36 (2009) L03805.

[6] J. G. Ferman and J. D. Shanklin, Nature, 315(1985) 207 - 210.

[7] C.E. Jung, Tellux XIV, 4, (1962) 336-337.

[8] R. D. Bojkov, V. E. Fioletov and S. B. Diaz, Geophysical Research Letters, 22, 10 (1995) 1249 - 1252.

[9] P. M. Banks and G. Kockerts, Aeronomy, Part A, Academic Press New York London, 1973.

[10] R. S. Solarski, Science, 256 (1992) 342 - 349.

[11] J. B. Kerr and C. T. MCElory, The Automated Brewer Spectrophotometer, Atmospheric Ozone, Proceedings of Quadrennial Ozone Symposium, Greece, International Ozone Commission, 1984, p. 396.

[12] U. Kohler, U.R. Hartmanns Gruber, and W. Attmanspacher, Atmospheric Ozone Proceedings of Quadrennial Ozone Symposium, International Ozone Commission (IAMAP),1984, 402.

[13] M. A. Bondarenko, O. E. Bazhenov, and M. V. Grishaev, Atmos. Ocean. Opt. 19, 9 (2006) 699-702.

[14] B. H. Subbaraya and S. Lal, Journal of atmospheric and Terrestrial Physics, 56, 12 (1999a) 1557 - 1561.

[15] H. Zou, J. Geophys, Res. 90, 10 (1996) 463.

[16] N. P. Chapagain, Total Ozone Measurements Over Kathmandu Using Brewer Spectrophotometer, Thesis, Master of Technology, Andhra University, India, 2003.

[17] N. P. Chapagain, Quest-Journal of Kathmandu Bernhardt College, 1, 1 (2013) 1-6

[18] S. Bairs, Geophysical Research letters, 23, 8(1994) 833 - 836.

[19] W. A. Mathews, Atmospheric Ozone: Natural and Manmade Variations, Ozone Depletion, edited by Mohammed Ilyas and Published by University of Science of Malayasia and UNEP, 1991.

[20] WMO, Report of the International Ozone Trends Panel, Global Ozone Research Monitoring Project Report No. 18, Published NASA, NOAA, FAA and UNEP, 1988.

[21] A. M. Zvyagintsev, L. B. Anan'ev, and A. A. Artamonova, Opt. Atmos. Okeana, 23, 3 (2010) 190-195. 
Narayan P. Chapagain/ BIBECHANA 13 (2016) 9-17 : RCOST p.17 (Online Publication: Dec., 2015)

[22] O. E. Bazhenov, Atmospheric and Oceanic Optics, 25, 2 (2012)142-146.

[23]B.H. Subbaraya and S. Lal, Space Research in India: Accomplishments and Prospects, PRL Alumni Association, Ahmedabad, 1999. 